a place in ophthalmology which can be described as both ethical and valuable.

With this in mind it is desirable that comprehensive contributions to the relevant literature should be seen to build on this late foundation and not to turn the clock either back or too far forwards with ill-advised haste. In this respect, this book falls short of what is required. It represents a very personal account of Dr Scharchar's views, with much detail about his surgical techniques and the value of his design of implant. His views are unsupported by statistical evidence of his own, and no mention is made of the need to make further study and assessment of results and complications in a proper scientific manner.

Because of the number of astonishing and possibly dangerous assertions such as that $\alpha$-chymotrypsin causes glaucoma and delayed wound rupture, or that endothelial dystrophy does not constitute a contraindication to implant surgery, this book should be regarded as unsuitable for postgraduate study, unless read with welldeveloped critical faculties. The text is not assisted by medical illustrations of poor quality.

This book reflects an attitude in favour of implantation for almost every type of patient with cataract and belittles the disadvantages, attributing most complications to faulty surgical technique rather than to unsatis- factory clinical judgment. Such teaching could easily lead the inexperienced surgeon and his patients into serious trouble.

A. D. MCG. STEELE

Colour Vision. By Gerald S. Wasserman. Pp. 224. £13.40. John Wiley: Chichester. 1978.

This useful historical review will be of interest to both the expert and the layman. It is eclectic in the sense that it starts with Newton, even though the study of colour vision received a considerable impetus a century and a half earlier at the hands of Leonardo da Vinci. The author spends quite some time in grappling with psychological concepts-a thankless task, in your reviewer's opinion. His description of fundamental physiological studies on primates is brief to the point of being curt, but perhaps this restores a recent imbalance in the literature on colour. It is interesting to witness the resuscitation of long-laid ghosts, and to see recent ones confirmed. For example, the so-called principle of univariance (p. 91), linked with Rushton's name, was stated by Einstein at the beginning of this century and really stems from photochemical principles datable to the middle of the last century. But if we credit someone with a discovery often enough he will make it one day.

R. A. WEALE

\title{
Correspondence
}

\section{Experimental branch retinal vein occlusion}

SIR, I was interested to read the 3 publications ${ }^{1-3}$ in the June 1979 issue of the British Journal of Ophthalmology on experimental branch retinal vein occlusion (BRVO). We have had similar results in our identical experimental studies on BRVO, conducted over the past 6 years, with a follow-up of eyes in rhesus monkeys up to 2 years (not published as yet). While I support, in general, the findings of the authors on BRVO, I take very strong issue with some of the statements regarding our work on central retinal vein occlusion (CRVO) by Hamilton et $a{ }^{1}{ }^{1}$ and particularly in the anonymous editorial ${ }^{4}$ preceding that paper.

The editorial ${ }^{4}$ appears to make the mistake of equating CRVO with BRVO. The articles describe studies of BRVO and not CRVO, and the author of the editorial has drawn conclusions from those studies on the BRVO only. CRVO and BRVO are 2 very distinct conditions. The anatomy of the CRV, the various physiological and pathological aspects of its blood flow, and the pathogenetic factors in its occlusion are very different from those of the BRV. Moreover, studies reported do not even reproduce all aspects of the clinical syndrome of BRVO in the animals. To apply the findings to CRVO (without doing any exhaustive studies on CRVO) is in my view ridiculous.

In the field of research, the emergence of new facts and evidence makes us modify our views as we go along, provided we keep an open scientific mind. My studies, conducted in the early 1960s and published in $1965,{ }^{5}$ were conducted on a small series and, more importantly, before the advent of fluorescein angiography and it was impossible to determine the extent and type of occlusion of retinal vessels under those experimental conditions. Our recent studies ${ }^{6}$ clearly revealed the limitations in those earlier studies, and the consequent erroneous impressions. Recently we pointed out ${ }^{6}$ the discrepancy in the 1965 study in the light of our recent findings, but the author of the editorial has taken no notice of that fact. The editorial writer even misrepresents our current views on the subject.

According to the author of the editorial, 'the difference in the clinical appearances [between the CRVO and BRVO] are due to differences in the site of the obstruction'. Site of occlusion undoubtedly plays an important role in the severity of the clinical picture of CRVO, and we strongly emphasised this fact in our paper, ${ }^{6}$ but that does not explain everything about the pathogenesis of CRVO. For example, one-third of the patients with CRVO have ocular hypertension or chronic simple glaucoma, whereas in BRVO the incidence is no higher than in the general population.

The author admits the presence of 'ischaemic capillaropathy'. This can be reproduced by more mechanisms than one. No doubt isolated venous occlusion by itself 
(if no significant collaterals exist before the site of occlusion) can produce it, as is evidently the case in BRVO and in a number of cases of CRVO (if the site of occlusion in the latter is at the lamina cribrosa or close to it, and no collaterals are available). In my paper in $1971^{7}$ (on page 1009) I stated that in some cases, primary retinal venous obstruction in the closed retinal circulation may produce secondary retinal arterial insufficiency'. However, other factors can also produce retinal ischaemia, even if the site of occlusion in the CRV is somewhat further back. A transient retinal ischaemia seems to play a very important role in the majority of patients with CRVO. There is clinical and experimental support for this. Among the patients with CRVO there is a high incidence of cardiovascular disorders, and patients with these abnormalities develop marked systemic arterial hypotension during sleep. It is well known that a vast majority of nonembolic arterial occlusive episodes in the brain and eye develop during sleep (e.g., cerebral stroke, anterior ischaemic optic neuropathy, central retinal artery occlusion), so that the patients discover them on waking in the morning. Transient arterial hypotension and consequent fall of perfusion pressure leads to transient ischaemia for a few hours. Similarly, in CRVO, ischaemic insult develops most often during sleep, and in the majority the visual defect is discovered on waking up in the morning. Fluorescein fundus angiography, even a few hours after the discovery of defective vision, shows a fairly reasonable arterial circulation because of the recovery of systemic blood pressure. A normal arterial blood flow, on fluorescein fundus angiography, further indicates that there is no organic occlusion of the central retinal artery in these eyes. To get this transient retinal ischaemia one does not require central retinal artery occlusion-in fact, there is no central retinal artery occlusion in these eyes. In our recent experimental studies ${ }^{6}$ we used transient clamping of the central retinal artery simply as an experimental means to produce transient ischaemia, and did not imply at any time that there was an organic central retinal artery occlusion in a clinical situation. To attribute a statement like 'progressive capillary closure in retinal vein occlusion is due to arterial occlusion' to $u^{6}{ }^{6}$ represents either gross ignorance of our work or deliberate misrepresentation. In fact, we mention 'retinal ischaemia' as a most probable cause of capillary obliteration-a view currently accepted on the subject, and also admitted in the editorial. It is worth pointing out that on serial sections of the optic nerve in an eye with CRVO Stowe et al. ${ }^{8}$ showed $a$ definite occlusion of both the central retinal artery and vein. This would represent an occasional eye with CRVO, where in fact there could be an organic occlusion of the artery in addition to the occlusion in the CRV, as was thought in my original study. ${ }^{\mathbf{5}}$

Thus, this editorial did not at all do justice to our latest view ${ }^{6}$ on the subject of the pathogenesis of CRVO; but in fact misrepresented us. To set the record straight, let me restate our current views ${ }^{6}$. In the pathogenesis of CRVO there is no organic occlusion of the central retinal artery, but there is a transient retinal ischaemia which 'acts as a triggering mechanism in an already diseased CRV predisposed to haemorrhagic retinopathy'6; and while the site of occlusion in CRVO is an important factor, it is not the only factor in the pathogenesis of the CRVO, which is 'multifactorial'. To lump CRVO and BRVO into a single entity of 'retinal vein occlusion' has no justification whatever, and represents a serious error of judgment leading to all the confusion.

S. S. HAYREH

Department of Ophthalmology,

University of Iowa Hospitals and Clinics, Iowa City,

USA.

\section{References}

${ }^{1}$ Hamilton AM, Kohner EM, Rosen D, Bird AC, Dollery CT. Experimental retinal branch vein occlusion in rhesus monkeys. I. Clinical appearances. Br J Ophthalmol 1979; 63:377-387.

${ }^{2}$ Rosen DA, Marshall J, Kohner EM, Hamilton AM, Dollery CT. Experimental branch vein occlusion in rhesus monkeys. II. Retinal blood flow studies. $\mathrm{Br} \mathrm{J}$ Ophthalmol $1979 ; 63: 388-392$.

${ }^{3}$ Hockley DJ, Tripathi RC, Ashton N. Experimental branch vein occlusion in rhesus monkeys. III. Histopathological and electron microscopical studies. Br J Ophthalmol 1979; 63:392-411.

${ }^{4}$ Editorial: Retinal vein occlusion. $\mathrm{Br} J$ Ophthalmol 1979; 63:375-6.

${ }^{5}$ Hayreh SS. Occlusion of the central retinal vessels. $B r J$ Ophthalmol 1965; 49:626-45.

${ }^{6}$ Hayreh SS, van Heuven WAJ, Hayreh MS. Experimental retinal vascular occlusion-I. Pathogenesis of central retinal vein occlusion. Arch Ophthalmol 1978; 96:311-23.

${ }^{7}$ Hayreh SS. Pathogenesis of occlusion of the central retinal vessels. Am J Ophthalmol 1971; 72:998-1011.

${ }^{8}$ Stowe GC, Zakov ZN, Albert DM. Central retinal vascular occlusion associated with oral contraceptives. $\mathrm{Am} \mathrm{J} \mathrm{Oph-}$ thalmol 1978; 86:798-801.

SIR, The misinterpretation of Mr Hayreh's paper $^{1}$ was certainly not deliberate. If it was misinterpreted this occurred because the points raised were not very clearly put in the original paper. In that paper $\mathrm{Mr}$ Hayreh repeatedly talks about transient arterial stasis or occlusion-for example, on p. 318 in the first column; on p. 320 in the first column; on p. 321 he suggests that arterial insufficiency acts as a trigger mechanism in the already diseased central retinal vein (CVR). Obviously, I assumed that he meant that the ischaemia of the capillaries was secondary to the arterial disease. I am sorry if this is not what he meant.

It appears that Mr Hayreh's and our own views are really not as different as they used to be and there is considerably more agreement between us than there was before. Nevertheless, I stand by our Group's opinion that: (1) The clinical picture of both CRV occlusion and BRV occlusion is produced by outflow obstruction and the differences in appearance are due to the differences in siting of the occlusion. Chronic simple glaucoma in CRVO does not alter my views; it is just one factor which contributes to or precipitates venous stasisprobably when flow is at its lowest, intravascular pressure is at its lowest and intraocular pressure at its highest. (2) The disagreement between us, which is now very narrow, is on the production or pathogenesis of ischaemic 
capillaropathy. We suggest that the primary lesion is in the vein and that raised intravascular pressure, secondary to outflow obstruction, causes stasis and ischaemia and the clinical picture. This is what our experiments confirmed and we believe it to be so in the human situation as well.

I certainly am glad to see Mr Hayreh alter his views in the light of recent experimental evidence and I can assure him that the misinterpretation was not deliberate but a genuine misunderstanding of some of his statements.

Moorfields Eye Hospital,

EVA KOHNER

City Road,

London EC1V 2PD.

\section{Reference}

${ }^{1}$ Hayreh SS, van Heuven WAJ, Hayreh MS. Experimental retinal vascular occlusion-I. Pathogenesis of central retinal vein occlusion. Arch Ophthalmol 1978; 96:311-23.

[This correspondence is now closed.-ED, BJO.]

\section{Obituary}

\section{John Scully, MD, DPH, DOMS}

Dr John Scully, who died earlier this year, graduated from Manchester Medical School in 1931 and in the 1930s was appointed oculist to the then Salford Education Department. Thereafter, apart from a break for war service in the RAMC, he devoted himself to the care of children with visual defects and squint in this area. This work continued in the Salford Area Health Authority (T) team until his reluctant retirement a few months before he died.

In 1968 he received the MD from the University of Manchester for work on the epidemiology of squint and amblyopia. He had a long association with the Royal Eye Hospital in Manchester, where he was SHMO, and he remained an honorary clinical assistant at this hospital until his death. He was a very kindly and unassuming doctor and is remembered with affection by many of his young patients and their parents.

\section{Notes}

\section{Glaucoma congress}

The International Glaucoma Congress and the American Society of Contemporary Ophthalmology will hold their joint annual meeting in Orlando, Florida, on 9-15 March 1980. Details from Dr John Bellows, American Society of Contemporary Ophthalmology, 6 North Michigan Avenue, Room 1110, Chicago, Illinois 60602, USA.

\section{Retinal detachment surgery}

'Retinal detachment surgery-strategy and tactics' is a course approved for 14 hours of CME I credit, sponsored by the Manhattan Eye, Ear and Throat Hospital and scheduled for 14-15 March 1980. Further information from James S. Schutz, MD, Manhattan Eye, Ear and Throat Hospital, 210 East 64th Street, New York, NY 10021, USA.

\section{Consilium Europaeum Strabismi Studio Dedtium}

The 11th meeting of the CESSD will take place at the Institute of Child Health, Guilford Street, London WC1, on 18-19 April 1980 prior to the European Ophthalmological Congress in Brighton. Details from Miss Barbara M. Lee, Moorfields Eye Hospital, High Holborn, London WC1 7AN.

\section{Cadaver lacrimal surgery}

The sixth annual Boston lacrimal course, newly expanded with inclusion of cadaver lacrimal surgery, will be held on 5-6 June 1980 in Boston. Details from the Office of Continuing Education, Boston University School of Medicine, 80 East Concord Street, Boston, Mass. 02118, USA.

\section{Ultrasound}

The 8th symposium of the Societas Internationalis de Diagnostica Ultrasonica in Ophthalmologia (SIDUO) will be held in Nijmegen, Holland, on 16-19 September 1980. Details from Dr Johan M. Thijssen, St Radboudhospital, 6500 HB Nijmegen, Holland.

\section{European Ophthalmic Pathology Society}

The European Ophthalmic Pathology Society held its annual meeting in Brussels on 14-17 May 1979. Dr Hugh Greer, of Melbourne, Australia, was the guest of honour. The scientific programme included 39 case presentations by members and guests, and 17 countries were represented. For each presentation a protocol, histopathological sections, and appropriate clinical or macroscopic transparencies were provided.

The majority of case presentations dealt with inflammatory and metabolic disorders involving the globe, orbit, or eyelid, and the discussion was concerned predominantly with the nature of the biochemical disturbance. Malignant disease was also a prominent subject of the presentations, and the remainder of the cases provided examples of congenital malformation of the ocular tissues.

The 33 members who attended were: $K$. Arnesen (Norway); N. Ashton (UK); J. Babel (Switzerland); E. Balestrazzi (Italy); D. R. Barry (UK); P. Bec (France); M. Brihaye van Geertruyden (Belgium); A. Brini (France); J. G. Cunha-Vaz (Portugal); B. Daicker (Switzerland); P. Dhermy (France); P. C. Donders 